\title{
Analysis of Worker Performances Using Statistical Process Control in Fish Paste Otak-otak Food Industries
}

\author{
Mila Faila Sufa ${ }^{1}$, Nazrul Iszhar Ishak ${ }^{2 *}$, M. Zulafif Rahim ${ }^{2}$, Mohd Rasidi Ibrahim ${ }^{2}$ \\ ${ }^{1}$ Department of Industrial Engineering, Universitas Muhammadiyah Surakarta, Jawa Tengah 56102, Indonesia \\ ${ }^{2}$ Faculty of Mechanical Engineering and Manufacturing, Universiti Tun Hussein Onn Malaysia (UTHM), 86400 Parit Raja, \\ Batu Pahat, Johor, Malaysia, *Corresponding email : gd160060@ siswa.uthm.edu.my
}

\begin{abstract}
This research focuses on the improvement of Small and Medium Enterprises through the used of Process Statistical Control (SPC). An industry that focuses on the fish paste (known as "otak-otak") production was taken as the case study in this research and the problems analysed are based on the real industrial experiences. The data collection for control charts were recorded for two weeks consisting of working time for each operator. The data were collected in subgroup of 16 with sample size of 5 . The collection of data for weight of product was recorded randomly for the whole production line, while data collection of working time of operation was taken randomly from each operator every 30 minutes of the working hour. From this study, there are several problems had been detected in the process that been categories in six element that is people, method, measurement, machine, environment and materials. There were lack of motivation, lack of skill, lack of supervision, manual operation, lack of standard of procedure, waiting time in process, weight-based operator, lack of quality check, not using weight scale, conveyer that sometimes got stuck, spoon for tools, no automation, poor layout arrangement, talking while working, small working space, lack of hygiene, waiting time for material and easily spoiled. The findings can be used as the guideline to the industries for future production improvement. The industries would focus on elimination or reduction of the problems through their innovative solution.
\end{abstract}

Key words : fish paste otak-otak, food process, statistical process control, worker performance

\section{INTRODUCTION}

The fish paste (known as otak-otak) is very famous food that can be found in Malaysia. This research is focusing on this type of food. The food industry has been a part of the service sector in Malaysia. This sector is largely influential in the growth of economy in Malaysia. From 2011 to 2012, the total food and beverage export remained stable at RM 15.5 billion [1].

\subsection{Food Processing Industry}

The food processing industry better suits the flexible organizational structures which can change at various stages of production process that can fulfil consumers' demand [2]. The food industry has become a key growth area in Malaysia [3], another research [4] implemented Smart Inventory Management System for preservation of food. While for performance evaluation of the supply chain may follow lean and green philosophies to obtain the best food product [5].

Manufacturing development like employment generation, foreign exchange savings and value-added creation has been contributed by this industry [6]. Human factor is important to industrial and system engineering because of the prevalence of humans within the industrial system. It is human who, for the most part, is called on to design, manufacture, operate, monitor, maintain and repair the industrial system. In each of these cases, human factor should be used to ensure that the design meets the system requirement in performance, productivity, quality, reliability and safety [7].

Improvement of worker productivity performance measure has been one of the major concerns in manufacturing firms [8] and has been one of the objectives in any firm [9]. Due to some degree of limiting factor in productivity, companies cannot achieve the desired break-even or provision of inputs for good output. Low profitability or poor profit margin is the result of poor productivity [10].

Quality of production and manufacturing worker performance can be affected by this limiting factor [11]. Many factors have been considered and studied regarding poor output in manufacturing industries, and this factor will affect productivity. The factor that affects productivity the most is workers in the manufacturing industry [12].

A company's bottom line is usually affected by production worker performance and productivity. To increase productivity, the factors affecting employee performance must be understood [13]. A lot of factors that affect worker performance include power or energy infrastructure, trainings, motivations, machines reliability, technology and technological changes, work safety place, standard equipment, leadership effectiveness, time management and process charge [12]. 


\subsection{Statistical Process Control (SPC) in Food Industry}

Statistical process control (SPC) involves the use of various methods to measure and analyse a process. Improving the quality of the process output, reducing process variability and achieving process stability and solving processing problems are overall objectives of statistical process control (SPC) [14]. Food industry possessed unique characteristics of production processes, SPC is effective towards the improvement in process performance [15]. Uses of SPC techniques enables plant operators to take corrective actions quickly when needed before the variation affects significantly [16]. SPC can be a versatile technique for managing quality improvement in the food industry and sustaining the quality of food products [17]. SPC can reduces the risk of processing and selling unsafe products because it is a cost-effective program which is fairly useful in a small-scale industries [18].

In statistical process control (SPC), control charts are widely used. The two types of variation have been the underlying principle of control charts that is a random variation (variations present if the process is in statistical control) and assignable variation (variations that depart from statistical control), on the corrective actions to be performed when the control charts identify that the process has gone out of statistical control [19]. The process in statistical control can be determined with graphical technique as statistics is computed from measured values of certain process characteristics, which are plotted over time, also known as control chart [20]. Control charts, as a means of simple trend analysis, provide visual aids to interpretation of data that are more readily understood than are tables of data values $[21,22,23]$.

\section{METHODOLOGY}

The assessment was conduct at an "otak-otak" company in Malaysia. This company is categorized as small and medium enterprise. This company produces "otak-otak" as many as 64,000 units per day. This company opens for business 5 days per week from Monday to Friday. The company operates for 8 hours starting at 8.00 in the morning, rest at 1.00 in the afternoon until 2.00 in the evening, and finishes at 5.00 in the evening. Figure 1 shows the production line at the "otak-otak" company. This company still uses manual method of production. This manual production method is implemented in the production line only.

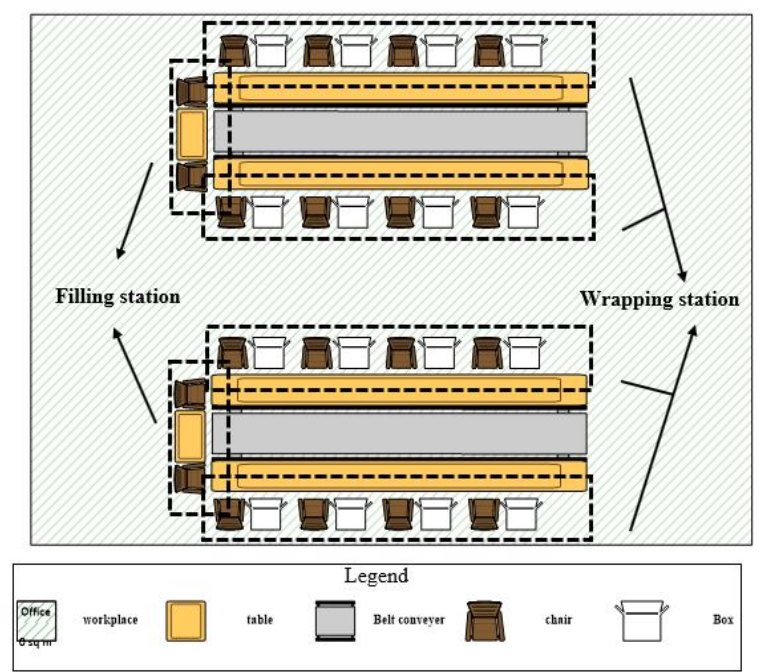

Figure 1: Illustration of production line in food industries. The company has two production lines. Each of the production line consists of two stations. The first station is filling station, and second station is wrapping station. Each production line also consists of one conveyer belt mounted in a long table. This table can load ten operators that consist of two operators for filling station, and eight operators for wrapping station. One of the production lines will be monitoring for this project to collect data. The data collected was time taken for each operator for these two stations.

The data collection for control charts were recorded for two weeks. The data consisted of working time for each operator. The data were collected in subgroup of 16 with sample size of 5 . The collection of data for weight of product was recorded randomly for the whole production line, while data collection of working time of operation was taken randomly from each operator every 30 minutes within working hour.

\section{RESULT AND DISCUSSION}

The analysis was conducted at production line using manual operation. This situation was conducted prior to improvement in production line at the company. Manual operation as done using fully human labour to produce its product. This analysis was conducted to measure the performance in the production line. This analysis was also conducted to observe the process whether the process was needed for improvement or not. The data were converted into control charts to observe whether the process was in control or not. The sample control charts of this analysis are shown in Figure 2. 


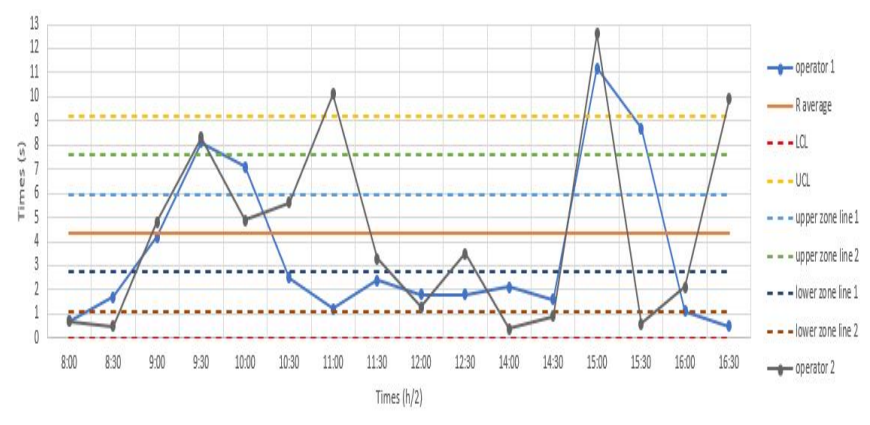

Figure 2: Sample of control chart in wrapping station

Table 1 shows the days of out of statistical control based on the control chart that had been constructed within two weeks. After analysis was conducted in the production line, the results from this analysis were inserted into the cause and effect diagram.

The results were compiled in Table 1 for reference to the cause and effect diagram as illustrated in Figure 3. From this table, the sources that cause the process out of statistical control were collected. These sources of problem were compiled in the cause and effect diagram. This cause and effect diagram were based on the production line consisting of filling station and wrapping station. This cause and effect diagram consisted of six categories including people, method, measurement, machine, environment and materials. With these compiled sources of problem, the most important problem can be tackled. Figure 3 shows the cause and effect diagram for production line of "otak-otak". These sources of problem were collected through observation during data collection and time taken of process. The longest time taken from sample from the process was remarked and inserted to the cause and effect diagram.

Table 1: Process out of statistical control.

\begin{tabular}{cc}
\hline Operator & $\begin{array}{c}\text { Days of out of statistical } \\
\text { control }\end{array}$ \\
\hline 1 & 10 out of 10 \\
\hline 2 & 7 out of 10 \\
\hline 3 & 8 out of 10 \\
\hline 4 & 8 out of 10 \\
\hline 5 & 10 out of 10 \\
\hline 6 & 10 out of 10 \\
\hline 7 & 10 out of 10 \\
\hline 8 & 10 out of 10 \\
\hline 9 & 10 out of 10 \\
\hline 10 & 7 out of 10 \\
\hline
\end{tabular}

From this cause and effect diagram, the six categories had their own problems. From the people category, there was lack of motivation, lack of skill and lack of supervision. There was lack of motivation between operators, due to the specified target of production each operator had which are 1500 pieces of products. Poor product ("otak-otak") quality was also due to lack of skill of operator to fill the paste in the leaves. The skill of weight assumption of operator must be trained for a long time to get the right weight of product (24-26 grams). The lack of supervision also contributed to poor product quality because there was lack of quality check in that company.

For method category, three sources that contributed to poor product quality are manual operation, lack of standard of procedure and waiting time in process. This company still used manual operation in their production line. So, there were a lot of operators in this production line. The process that can be automated was still not applied in this production line such as filling station. Lack of standard procedure in working time contributed to the poor product quality. Waiting in process occurred when the filling station did not match the wrapping station. So, there was product delay in the wrapping station due to faster speed at the filling station.

In measurement category, the sources that contributed to the poor product quality was the weight-based operator, lack of quality check and not using weight scale. Due to manual operation, the weight of product was based on operator. Operator assumed the weight of product that would fill the leaves without scaling due to the limited time. There was also lack of quality check. Due to lack of supervision, the product did not get checked frequently, making poor product quality to avoid the inspection. The operator also did not use weight scale to weigh the product in accordance to the specifications of that company which is $25 \pm 1$ grams. Without proper training, it was difficult to train the operator to put exact weight of paste in the leaves.

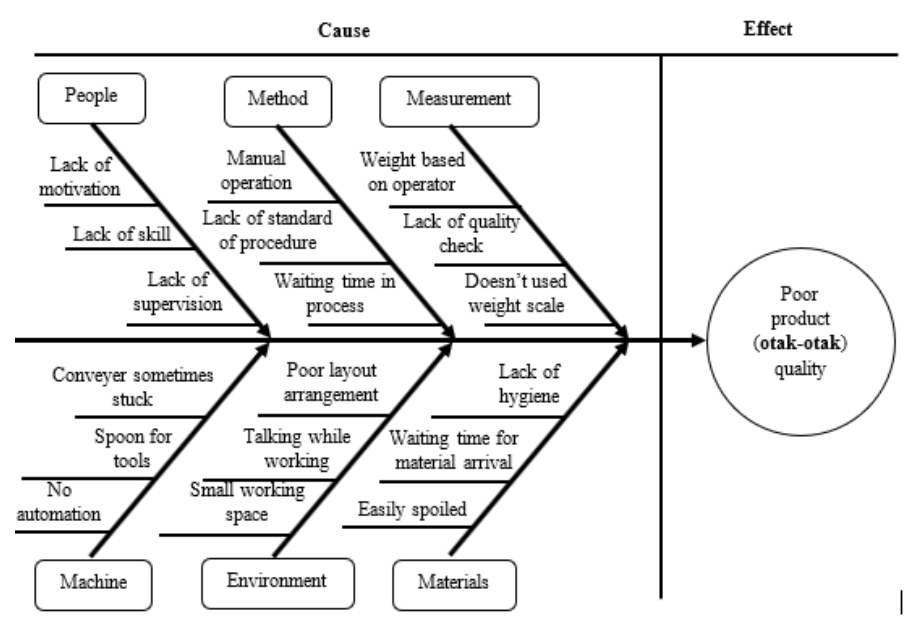

Figure 3: Cause and Effect Diagram of "Otak-otak" Production.

In machine category, the sources that contributed to the poor product quality was the conveyer that sometimes got stuck, spoon for tools and no automation. The problem of stuck conveyor was due to the paste stuck on the conveyer. This showed that the paste on the leaves sometimes faced the conveyer belt instead facing the opposite of the conveyer belt. 
This was because the operator wrongly put the paste that filled in the leaves on the conveyer belt. The operator also used a spoon to fill the paste in the leaves. The spoon measured the weight of product that will be put on the leaves. This spoon cannot measure the exact amount of paste in the leaves due to different shapes of spoon. The production line was still using manual operation, so there was no automation involved in the production line. The production line used $100 \%$ human labour to produce the product in the company.

The environment category in the company also contributed to poor product quality. The source of this contribution was poor layout arrangement, talking while working and small working space. The poor layout arrangement contributed to the non-value added in the process. The waiting time includes waiting time for the leaves to be refilled, for the paste to be refilled and fully occupied box to be taken from wrapping station to the delivery bay. Talking while working made the product pass through inspection and made the operator to lack of focus while working. The small working space also contributed to the former problem. The small working space made it easier for the operator to talk with each other.

Lastly, the material category also contributed to the poor product quality. This source of problem was lack of hygiene, waiting time for material and easily spoiled. When the manual operation was involved in the process, hygiene can be questioned due to a lot of human interaction. When there were a lot of human interaction, the material will be exposed to a lot of variables that can reduce the quality of the product. Poor layout arrangement should also be discussed. Due to poor layout arrangement, the waiting time for material cannot be avoided. Due to a lot of human interaction, the material would be easily spoiled. When food was involved in the production, hygiene is the main concern to be considered to keep the product quality to the maximum.

From Toyota Production System theory identifies seven waste [24] based on observation and brainstorming with the company, the critical process waste production can be identified, i.e. Waiting, Transportation and Defects. Since the most "from" waste contribution sources are from defects and process, furthermore these two sources may contribute to the emergence of other wastes. For example, the emergence of waste defects may contribute to the in increased transportation intensity and motion due to rework process of waste defects.

Apart from waste process, a mismatch of machine's setting develop also misalignment defects and various other geometrical wastes. The most contributor "to" waste is to defect and to waiting. As an example, the existence of waste motion in the form of different skills of operators can cause defects. Another example is waste transportation due to lack material handling that cause process waiting time production.
Based on the critical waste that has been identified, then analysis of the root of the problem using 5 Why's. The method 5 Why's is used by asking why several times so that actions that are in accordance with the root cause of the problem are found to eliminate problem [25]. The root of the problem is obtained through observation and brainstorming with company experts.

\section{CONCLUSION}

In this study, several sources of production problem were detected. The operators were not motivated to perform better as they are set to achieve the target within working hours. Lack of supervision of operator, made them not to follow the company rules. In fact, there is no standard of processing time allocated per product. Hence, there is no guideline of suitable processing time per product to ensure the targeted output can be accomplished within the allocated working hours. Without the use of weighing scale, the weight of product is inconsistent as the process of filling the paste to the leaves is based on weight assumption.

The speed of conveyer is inconsistent as most of the time, the paste stacked on conveyer shaft, slowing down the belting movement. With lack of supervision and inadequate standard operation procedure, non-value-added activities such as product waiting or operator waiting is typically happened. This consequently slowing down the product transfer process between stations as well as the total production time.

There are several approaches can be implemented in future such the use of standard operational procedure (SOP) based on process, layout arrangement based on lean manufacturing and automation, as widely used in the big manufacturing industries. With the proper SOP, the company can have better production control thus increases the production performance. Good layout arrangement also can reduce the waiting times in the production line while automation is known as able to increase the production rate, safety and hygiene of the raw material.

\section{ACKNOWLEDGEMENT}

The authors would like to acknowledge the Ministry of Higher Education (MOHE) Malaysia under Public-Private Research Network (PPRN) grant, Vot A082 and Universiti Tun Hussein Onn Malaysia (UTHM) under Postgraduate Research Grant (GPPS), Vot U743 for the research financial support

\section{REFERENCES}

1. Abu, F. (2016). A study on adoption of technology in SMEs food. Universiti Teknikal Malaysia Melaka.

2. Bogue, J., \& Ryan, M. (2000). Market-oriented new product development: Functional foods and the Irish consumer (Agribusiness Discussion Paper No. 27). Cork. 
National University of Ireland, Department of Food Economics.

3. Ayupp, K., \& Tudin, R. (2013). Malaysian food processing industry: Strategies for growth. International Journal of Business and Social Science, 4(16), 172-180.

4. Basa, J.J.A., Cu, P.L.G., Malabag, N.N., Naag, L.A.V., Abacco, D.F.P., Siquihod, M.J.M., Madrigal, G.A., Tolentino, L.K.S. (2019). Smart inventory management system for photovoltaic-powered freezer using wireless sensor network, International Journal of Emerging Trends in Engineering Research 7 (10), 393 - 397 https://doi.org/10.30534/ijeter/2019/057102019

5. Deshmukh, Y.P., Borade, A.B. (2019). Performance evaluation of the indian plastic processors supply chain: Implementing lean and green philosophies, International Journal of Emerging Trends in Engineering Research 7 (5), $1-14$ https://doi.org/10.30534/ijeter/2019/01752019

6. Ahmed, E. M. (2012). Malaysia's food manufacturing industries productivity determinants. Modern Economy, 2012(July), 444-453. https://doi.org/10.4236/me.2012.34057

7. Badiru, A. B. (2013). Handbook of Industrial and Systems Engineering (second). CRC Press. https://doi.org/10.1201/b15964

8. Borman, W. C. (2004). Introduction to the special issue: Personality and the prediction of job performance: More than the big five. Human Performance, 17(3), 267-269. https://doi.org/10.1207/s15327043hup1703_1

9. Ryan, A. M., Greguras, G. J., \& Plo yhart, R. E. (1996). Perceived job relatedness of physical ability testing for firefighters: Exploring variations in reactions. Human Performance, 9(3), 219-240. https://doi.org/10.1207/s15327043hup0903_3

10. Mazumdar, D., \& Mazaheri, A. (2017). Wages and Employment in Africa (1st ed.). https://doi.org/10.4324/9781315190624

11. McIntyre, M., Murphy, S., \& Mitchell, P. (2007). The Top Team: Examining Board Composition and Firm Performance. Corporate Governance, 7, pp. 547-561. https://doi.org/10.1108/14720700710827149

12. Uzorh, A. C., Okafor, B. E., Igbokwe, J. O., \& Nwosu, M. C. (2017). Quantitative analysis of factors affecting manufacturing workers performance in industry: Case study of plastic companies in Eastern Nigeria, using SPSS. Engineering and Advanced Technology Studies, 5(3), pp. 9-53.

13. Parvin, M. M., \& Kabir, M. M. N. (2011). Factors affecting employee job satisfaction of pharmaceutical sector.

14. Montgomery, D. C. (2005). Introduction to Statistical Quality Control (5th ed.). Business and Management Research, 1(9), pp. 113-123.

15. Lim, S. B. A. H. (2016). An exploratory study on statistical process control in the UK food industry.
Heriot-Watt University, UK, (January), 304

16. Dalgiç, A. C., Vardin, H., \& Belibağli, K. B. (2011). Improvement of food safety and quality by statistical process control (SPC) in food processing systems: A case study of traditional sucuk (sausage) processing. Quality Control of Herbal Medicines and Related Areas.

17. Lim, S., \& Antony, J. (2014). The implementation of statistical process control in the food industry: A systematic review. International Conference on Industrial Engineering and Operations Management, (9), 1683-1691.

18. Zhao, M. (2003). The Design of HACCP Plan for A Small-Scale Cheese Plant (University of Wisconsin-Stout).

19. Abraham, B., \& Ledolter, J. (2009). Statistical Methods for Forecasting (Vol. 234). John Wiley \& Sons.

20. Gryna, F. M. (1999). Quality and Costs. In J. M. Juran \& A. B. Godfrey (Eds.), Juran's Quality Handbook (5th ed., pp. 231-256). McGraw-Hill New York.

21. Jarvis, B.(2008). Statistical process control using microbiological https://doi.org/10.1016/B978-0-444-53039-4.00012-1

22. Raju, K. V. R. (2005). Quality control for processed foods. https://doi.org/10.1016/j.ejmp.2012.08.051

23. Wasusri, T., \& Maccarthy, B. (2001). Using spc chart techniques in production planning and scheduling: Two case studies. Management, (2000).

24. Liker, J.K. \& Meier, D. The Toyota Way. USA: Mc Graw Hill, 2006.

25. Rawabdeh, I. A (2005). A model for the assessment of waste in job shop environments," International Journal of Operations \& Production Management, 25(8), 800822, https://doi.org/10.1108/01443570510608619 